https://doi.org/10.31713/m1002

\title{
INFORMATION TECHNOLOGIES IN HYDROMECHANICAL METHOD OF AMBER MINING
}

Malanchuk Z.R.

National University of Water and Environmental Engineering (NUWEE), Professor, Doctor of Technical Sciences, Professor, Department of Development of Deposits and Mining, Ukraine

\section{Nadutyi V.P.}

Institute of Geotechnical Mechanics named after M.S. Polyakova (IGM), Professor, Doctor of Technical Sciences, Professor, Department of mechanics of machines and processes of mineral processing, Ukraine

\section{Korniyenko V.Ya.}

National University of Water and Environmental Engineering (NUWEE), Professor, Doctor of Technical Sciences, Professor, Department of Development of Deposits and Mining, Ukraine

\section{Malanchuk Ye.Z}

National University of Water and Environmental Engineering (NUWEE), Professor, Doctor of Technical Sciences, Professor, Department of Automation and Computer Integrated Systems, Ukraine

\section{Khrystyuk A.O.}

National University of Water and Environmental Engineering (NUWEE), Ph.D., Associate Professor, Department of Automation and Computer Integrated Systems, Ukraine

\section{Abstract}

The analysis results of possibilities of use of modern information technologies at control of process of extraction of amber from sand deposits are resulted. The expediency and efficiency of using artificial neural networks in the control of hydromechanical extraction of amber from sand deposits is shown. The structure of 
an artificial neural network which considers features of hydromechanical extraction of amber is offered.

\section{Introduction}

The object of research is the process of controlling the extraction of amber in the hydromechanical method of extraction from sand deposits.

Existing methods and technical means of implementing the management of the process of hydromechanical amber mining do not fully meet the requirements, namely, the existing control systems of mining facilities are reduced to ensuring the sustainability of certain parameters of the process. It is proved that the efficiency of hydromechanical mining plants, energy consumption, water, air consumption, as well as the amount of extracted useful component, directly depend on the duration of hydromechanical impact on the sand massif, ie the speed at which amber particles float to the surface. depends on a number of factors and technological parameters.

Today, amber mining requires the latest technologies and improvements in technical and technological means to intensify the mining process, which achieves higher productivity and efficiency, as well as reducing the negative environmental impact of the environment. The most effective is the introduction of modern automation tools in the process of amber mining, and in particular modern intelligent control methods that do not require significant modernization of existing technologies, but ensure the most efficient use of existing technological equipment, and have the prospect of improvement by ensuring high selection of optimal ratios of water and air consumption, and oscillation frequency of the working body.

\section{Analysis of the process of hydromechanical amber extraction}

The northern districts of Rivne region are characterized mainly by the occurrence of amber in sandy soils, which are characterized by the presence between the skeleton of the soil pores of water and air between them. Sandy soil becomes mobile when the balance between the soil skeleton and water pores is disturbed, and a slight influence of hydraulic flows can lead to the displacement of the massif and the transition of large masses of soil to a liquefied state. The transition of 
water-saturated sands to the liquefied state causes the destruction of the structure of the sands and their compaction under the action of its own weight or external influences. When the sand is liquefied, the bearing capacity is lost completely or partially and the fluid state arises as a result of the destruction of the structure and displacement of the sand particles relative to each other, accompanied by the formation of a denser particle placement and reduced porosity. [1-4].

The phenomenon of liquefaction occurs when the destruction of the structure and the possibility of compaction of sand; full, or close to full, saturation of sand with water.

When conducting research amber sand deposit at the initial stage goes into a state of rarefaction, and then it is compacted. The duration of water-saturated sands in a rarefied state is much shorter than the time of soil compaction. In our opinion, and based on the analysis of literature sources, the compaction process is more studied than the liquefaction process, so experimental studies of the liquefaction process, the process of amber surface and the time of transition of sandy soil to compacted state require additional research. To create the necessary conditions for the surface of amber to investigate the parameters of vibration and the use of water and air when exposed to sand.

It is known from studies [5-8] that the movement of sand in the vibrating fluidized bed is not subject to the law of motion of particles in airless space. In addition to the force of gravity, the trajectory of the sand layer is significantly influenced by the parameters of the environment. When tossing, a vacuum is formed, when falling - an increase in medium pressure. The lower layers of sandy soil have a larger pressure drop than the upper ones, therefore, the air is displaced from below and compaction is carried out between the particles.

Thus, the vibrating fluidized bed of sandy soil behaves like a pump that pumps the gas-liquid mixture to the surface, capturing the particles of amber and transporting them to the top. The rate of particle rise from the bottom to the top depends on the vibrational excitation of the array, the vacuum of the medium, the saturation of air bubbles and the viscosity of the medium.

The pressure drop depends on the frequency and amplitude of the oscillator, the height of the layer, the particle size and humidity of 
the sandy soil, as well as the coefficient of friction of the particles against each other. The intensity of the pumping action of the vibrating fluidized bed is characterized by three parameters: the pressure above and the vacuum under the vibrating fluidized bed, the pressure drop in the layer.

The creation of the vibro-boiling layer of the soil is influenced by the following parameters: 1) the amplitude of oscillations; 2) frequency of oscillations; 3) coercive force; 4) water pressure; 5) air pressure; 6) geometric location of oscillators.

The method of hydromechanical amber mining is implemented with the minimum amount of reclamation work required for overburden work, transportation costs, with a small amount of water supplied to the array under a pressure of $0.1-0.2 \mathrm{MPa}$. This confirms the high energy and economic efficiency of the method.

Experiments have shown that the amount of water is determined by the porosity of the soil in the treated area. When implementing the method of water filtration gradient outside the treated array can be neglected, because the process is transient.

The supply of air to the sand massif intensifies the process of amber rising. An increase in air flow above the rational leads to a decrease in the rate of ascent and the formation of channels through which air freely reaches the surface of the field and there is no vibration of the whole array.

When comparing the operation of the installation in different operating modes, the minimum density of $1600 \mathrm{~kg} / \mathrm{m}^{3}$ of sandy environment, which creates a vibrating agent, are observed with simultaneous water and air supply and water supply without air supply at a vibration frequency of 26-36 Hz.

During the operation of the installation, a certain working zone of the suspended soil and its boiling with the removal of solid pieces of amber in the surface layers of the soil mass was observed.

The rate of exit to the surface of amber depended on the intensity of the process, namely the action of oscillations of the working body, the supply of gas-air mixture and the physic-chemical properties of the soil.

The following was observed during experimental studies:

- the rate of amber float depends on the oscillation frequency of the working body, the amplitude and density of the medium and has its extremum; 
- the density of the medium significantly affects the creation of conditions for rapid emergence of amber, which affects the productivity of the hydromechanical method of amber mining;

- there are values of parameters of oscillations and supply of air and water at which the suspended environment is not created, and there is no rise of amber on a field surface.

Intensify the process of amber mining is possible with the use of oscillations, supply to the soil mass of water, or water and air.

Creating the desired density of the medium depends on the supply of gas-liquid mixture, oscillation frequency and geometric parameters of the working body and its weight. The water supply affects the duration of the vacuum.

\section{Main parameters of control systems}

Synthesis of modern mining management systems requires the establishment of structural relationships between input and output parameters of the object, the correct choice of controlled parameters and control effects. Analyzing the results of research, we found that the main regulatory parameters in hydromechanical amber mining are water and air consumption, frequency and amplitude of oscillations of the working body, adjustable - the density of amber-containing medium and the rate of amber ascent. The main disturbing factor influencing the regulating and regulated parameters is the physical and geological properties of the formation. Based on this, we have developed and tested at the field a structural diagram of the relationship between the parameters of hydromechanical amber mining (fig. 1).

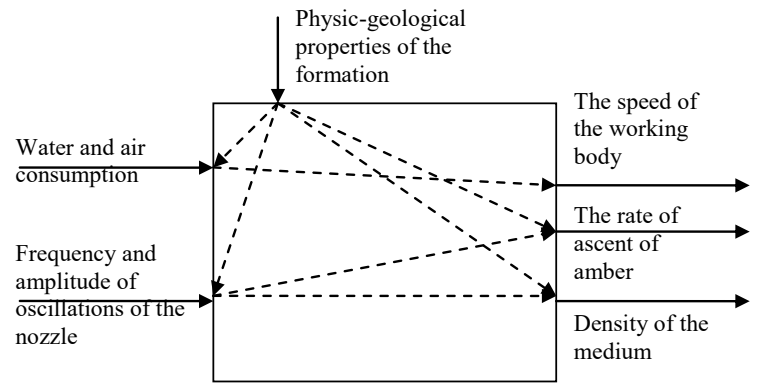

Fig. 1. Block diagram of hydromechanical amber mining management links 
Coordination of the hydromechanical complex of amber mining is provided by the dispatching service, which is responsible for the tasks of direct production management: centralized management of individual production sites and facilities; control of technological process of extraction and transportation of amber, and also a condition of separate responsible knots, regulation (if necessary) of processes by remote change of installations of the regulators carrying out stabilization of giving of working agents: the centralized account of quantity of the received product, material and power expenses, etc.. It is most expedient to apply a one-stage structure of operative management of a complex at which management and control of all process is carried out from the uniform central dispatching point where the control and measuring equipment is established. The central control room receives all the necessary information about the flow of technological processes at different production sites.

When carrying out the main technological process (actual extraction) the stabilization of parameters of working agents should be provided. For this purpose, control valves and diaphragms are installed on the pipelines.

\section{Hydromechanical amber mining control system based on fuzzy logic}

The problem of ensuring the maximum extraction of amber is solved by adjusting the parameters of the hydromechanical extraction. Based on the conditions of resource conservation and efficient extraction of minerals necessary time (over time) coordination of the required frequency of oscillation of the working body and the supply of water and air.

Significant uneven distribution of mineral deposits and differences in deposits and unpredictability of deposit conditions virtually preclude the use of traditional methods of regulating the parameters of the mining plant to ensure efficient amber mining.

One of the effective ways to solve problems of object management with nonlinear multiparameter characteristics in conditions of complete or partial uncertainty is the use of fuzzy logic with neural network adaptation. 
Fuzzy neural networks combine the advantages of neural networks and fuzzy output systems. Structurally, these are two separate mathematical devices.

Traditional formal-logical systems do not fully describe the nature of human reasoning and the course of thought as opposed to fuzzy logic, which makes it more natural.

Fuzzy control is a procedure or algorithm for obtaining fuzzy conclusions based on fuzzy conditions using the concepts of fuzzy logic.

When forming a control system based on fuzzy logic, we proceed primarily from the fact that the state of a complex dynamic system and the control effect of SAC are considered as linguistic variables that are evaluated by qualitative terms (means of natural language). Each term is considered as a fuzzy set and is formalized using the membership function.

The formation of the control effect is carried out on the basis of a set of rules that establish the relationship between the state of the dynamic system and the control effect in the automatic control system. Determination of the control effect is carried out by implementing the procedure of transition from the membership function to a specific numerical value, which is transmitted to the actuator.

The algorithm of operation of the control system based on fuzzy logic is shown in Fig. 2. The main stages can be implemented in different ways.

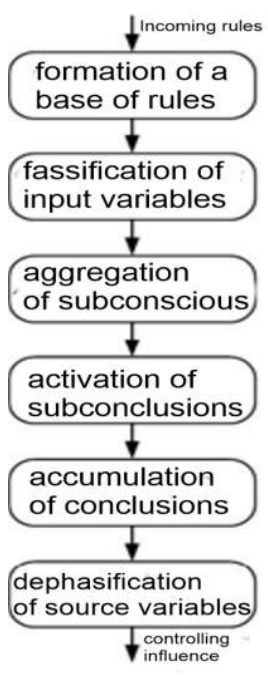

Fig. 2. General algorithm of fuzzy control system operation

Artificial neural networks are a set of models of biological neural networks, which are a network of elements - artificial neurons interconnected by synaptic connections.

The basic element of neural networks, an artificial neuron (Fig. 3) has a group of synapses unidirectional input connections connected to the outputs of other neurons, as well as an axon - the output channel through which the signal (excitation or inhibition) enters the synapses of subsequent neurons.

Each input is multiplied by a corresponding weight (weight) similar to the synaptic force, and all products are summed to determine the level of activation. 


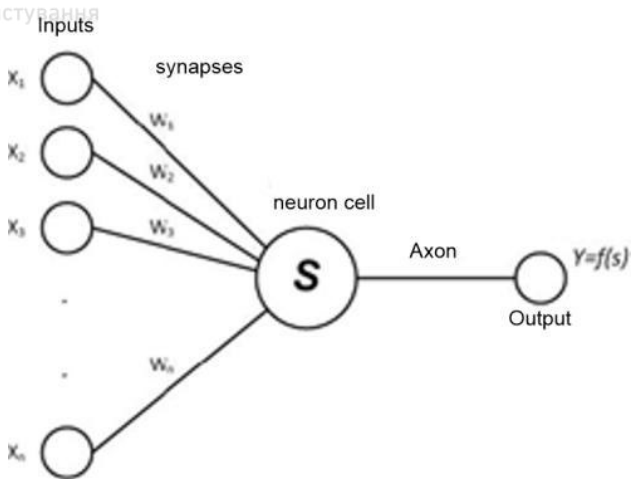

Fig. 3. Artificial neuron: $X_{1}, X_{2}, \ldots, X_{n}$ - inputs; $W_{1}, W_{2}, \ldots, W n$ - synaptic scales; $S$ - algebraic adder of weighted inputs; $Y$ - output; $f(s)$ - nonlinear activation function

As an activation function, it is advisable to use a nonlinear activation function of $S$ - similar type with saturation (sigmoid or logical function with saturation).

The neuron implements the scalar function of the vector argument. His mathematical model

$$
S=\sum_{i=1}^{n} W_{i} X_{i}+b
$$

where $W_{i}$ - synapse weight (when $\left.i=1,2, \ldots, n\right) ; b$ - offset value; $S$ - the result of summation; $X_{i}$ - component of the input vector (input signal) (when $i=1,2, \ldots, n) ; n$ - the number of neuron inputs.

The process of neural network functioning depends on the magnitude of synaptic weights. For a certain network structure (depending on the task), it is necessary to find the optimal value of all variable weights - this stage is called neural network training: the quality of the neural network to solve the tasks set before it depends on how well it is carried out.

As a result, the neural network generates an output signal $(Y)$ in accordance with the input signal $(X)$, implementing some function: $Y=g(X)$. If the network architecture is specified, the type of functional dependence is determined by the values of synaptic weights and network offsets.

There are many automatic control systems with fuzzy and neural network regulators, which significantly outperform traditional analogues when working with nonlinear and non-stationary objects 
(processes), which include the process of hydromechanical extraction of amber.

The advantages of developments using fuzzy logic and neural networks are:

- work in conditions of uncertainty about the nature of the input signals;

- reliable operation with a large number of input variables compared to traditional systems.

Disadvantages of using neural networks:

- long training time;

- the complexity of the analysis of the structure of the "trained" network, respectively, the impossibility of its optimization;

- the impossibility of entering apriority (expert) information to accelerate network learning.

Disadvantages of systems using fuzzy logic:

- the impossibility of automatic acquisition of knowledge in the process of functioning;

- the need to split universal sets into separate domains creates a maximum number of input parameters.

To increase the productivity of control systems and managed objects (processes), it is necessary to eliminate these shortcomings. This can be achieved by creating hybrid neural networks, where conclusions are made on the basis of fuzzy logic, and the corresponding membership functions are adjusted using a neural network learning algorithm. Developed systems can not only use a priori information, but also receive new knowledge in the process of functioning [9-13].

That is, a fuzzy neural network is a neural network with clear signals, weights, and an activation function, but t-norms or other continuous operations are used to combine them.

To develop a system of operation of the installation for hydromechanical extraction of amber should use a static model, which can be obtained by numerical factorial experiment based on the regressive static characteristics of the object. That is, the functional dependence of the yield of amber on the perturbing action: the properties of the formation, the conditions of extraction under the action of the control factor and regulatory actions. 
To study the control system of the amber mining plant on the basis of a neural network, three blocks of experimentally obtained data sets were used Training data, Testing data and Checking data. Using these data sets, the controller in the process of operation is adjusted to the variable parameters of the field and the operating conditions of the installation.

\section{Conclusions}

Thus, the analysis of technological parameters of amber extraction from sand deposits by hydromechanical method is carried out, which will ensure the minimum duration of impact on the array and reduce energy consumption and water consumption of extraction technology. The modern control system of the amber mining plant on the basis of fuzzy logic is considered.

In conducting the analysis, we took into account all the parameters of the amber mining plant, in particular the vibration frequency of the working body, water and air flow in the developed array. Ensuring the optimal ratio of these parameters by using a controller based on fuzzy logic will minimize energy consumption for the production process with the most efficient process.

\section{Bibliography}

1. Malanchuk Z., Malanchuk E., Khrystyuk A. Mathematical modeling of hydraulic mining from placer deposits of minerals / Mining of Mineral Deposits. National mining university, 2016. № 10 . pp. 18-24. DOI: http://dx.doi.org/10.15407/mining10.02.013

2. Malanchuk Z., Malanchuk E., Khrystyuk A. Results of experimental studies of amber extraction by hydromechanical method in Ukraine / EasternEuropean Journal of Enterprise Technologies, - 2016. Vol 3, №10(81). pp. 24-28. DOI: $10.15587 / 1729-4061.2016 .72404$

3. Malanchuk Z . Modeling the formation of high metal concentration zones in man-made deposits /Malanchuk Z., Korniienko V., Malanchuk Ye., Soroka V., Vasylchuk O. Mining of mineral deposits. ISSN 2415-3435, 2018, pp. 76-84 DOI: 10.15407/mining12.02.076.

4. Malanchuk Z. Results of experimental studies of amber extraction by hydromechanical method in Ukraine / [Z. Malanchuk, V Korniyenko, Y. Malanchuk and other.]. // Eastern European Journal of Enterprise Technologies. 2016. - pp. 24-28. DOI: https://doi.org/10.15587/1729-4061.2016.72404.

5. Malanchuk Z. Examining features of the process of heavy metals distribution in technogenic placers at hydraulic mining / Malanchuk Z., Malanchuk Ye., Korniyenko V., Ignatyuk I. Eastern-European Journal of Enterprise Technologies ISSN 1729-3774, 2017, pp. 45-51 DOI:10.15587/1729-4061.2017.92638. 
6. Arens, V. (2001). Physical and chemical geotechnology: text-book (p. 656). Moscow: State. Mining University Press.

7. Khrystyuk A. O. Analiz isnuyuchykh sposobiv ta tekhnolohichnykh zasobiv hidromonitornoho rozmyvu / Visnyk Inzhenernoyi akademiyi nauk. Kyyiv, 2015. Vyp. № 1. S. 236-240.

8. Malanchuk Z., Malanchuk E., Khrystyuk A. Simulation of the comminution process to complex processing of metal-bearing basalt raw material / Cambridge Journal of Education and Science, 2015. No 2 (14), July-December. pp. 542-549.

9. Malanchuk YE. Z., Khrystyuk A. O. Matematychne modelyuvannya protsesiv sverdlovynnoho hidrovydobutku rozsypnykh korysnykh kopalyn / Visnyk Inzhenernoyi akademiyi nauk. Kyyiv, 2015. Vyp. № 4. S. 187-194.

10. Khomenko O.Ye. Principles of rock pressure energy usage during underground mining of deposits / Khomenko, O.Ye.,Sudakov, A.K., Malanchuk, Z.R., Malanchuk, Ye.Z. / Naukovyi Visnyk Natsionalnoho Hirnychoho Universytetu, National Mining University of Ukraine, ISBN: 2071-2227, 2017, pp 34-43.

11. MalanchukZ.R.,MalanchukE.Z., KorniyenkoV.Ya. Modern geotechnical methods of management of the process of amber extraction / Multi-authored monograph:"Innovative development of resource-saving technologies of mining of minerals" Publishsng house «St. Ivan Rilsky» Mining and Mining University of Geology (Sofia, Bulgaria). - 2018. -P. 80-103.

12. Malanchuk Z. Physico-Mechanical and Chemical Characteristics of Amber / [Z. Malanchuk, V Moshynskyi, Y. Malanchuk and other.]. // Solid State $\begin{array}{llllll}\text { Phenomena. } & - & 2018 . & - & \text { pp. } & \text { 80-89. }\end{array}$ https://doi.org/10.4028/www.scientific.net/SSP.277.80.

13. Malanchuk Z. R. Results of studies on amber extraction by hydromechanical method / Z. R. Malanchuk, V. Ya. Kornienko, E. Z. Malanchuk. Mining of Mineral Deposits, 11(1), 2017, 93-99. DOI: http://doi.org/10.15407/mining11.01.093.

14. Malanchyk Z., Korniyenko V. Modern condition and prospects of extraction of amber in Ukraine / Proceedings of the 1st International Academic Congress "Fundamental and Applied Studies in the Pacific and Atlantic Oceans Countries". (Japan, Tokyo, 25 October 2014). Volume II.“Tokyo University Press".-2014. - P. 318-321.

15. Bulat A., Naduty V., Korniyenko V. Substantiations of technological parameters of extraction of amber in Ukraine / American Journal of Scientific and Educational Research. - No.2. (5) (July-December). Volume II.“Columbia Press”.New York. - 2014. - P. 591-597. 